\title{
Adherence, coping strategies and depression in highly antiretroviral-experienced patients CR Fumaz ${ }^{* 1}$, JA Muñoz-Morenoํ, MJ Ferrer ${ }^{1}$, N Pérez-Álvarez ${ }^{3}$, J Moltó ${ }^{1}$ and B Clotet ${ }^{4}$
}

Address: ${ }^{1}$ HIV Unit-Germans Trias i Pujol Hospital-Lluita contra la Sida Fdn, Badalona, Barcelona, Spain, ${ }^{2}$ HIV Unit-Lluita contra la Sida Fdn, Badalona, Barcelona, Spain, ${ }^{3}$ Lluita contra la Sida Fdn-Universitat Politècnica de Catalunya, Badalona, Barcelona, Spain and ${ }^{4}$ HIV Unit-Germans Trias i Pujol Hospital-IrsiCaixa Fdn, Badalona, Barcelona, Spain

* Corresponding author

from Ninth International Congress on Drug Therapy in HIV Infection

Glasgow, UK. 9-13 November 2008

Published: 10 November 2008

Journal of the International AIDS Society 2008, I I (SuppI I):PI76 doi:I0.II86/I758-2652-I I-SI-PI76

This abstract is available from: http://www.jiasociety.org/content/I I/SI/PI76

(C) 2008 Fumaz et al; licensee BioMed Central Ltd.

\section{Purpose of the study}

The purpose of this study was to assess whether the use of certain coping strategies might be associated with better adherence to antiretroviral therapy and better emotional status in highly antiretroviral-experienced patients who had survived the pre-HAART era.

\section{Methods}

Cross-sectional study with HIV-1 infected patients treated with antiretrovirals for at least 10 years. Adherence was assessed through self-reported information (15 previous days of medication intake), coping strategies through the Brief Cope questionnaire ( 3 being the maximum score per each scale) and depression through the HADS questionnaire ( 21 being the maximum score that indicates severe depression).

\section{Summary of results}

113 patients were included: $67.3 \%$ men, mean (SD) age: 44 years (7.8), CD4 cell count: 529 (269.4), nadir CD4 cell count: 210 (155.8), CV <50 copies: $86.7 \%$ of patients, years since HIV diagnosis: 15 (3.2), years on antiretroviral treatment: 12 (2.4). Adherence $>95 \%$ was reported by $71.7 \%$ of patients. Patients showed high scores in religion: 2 (1.7), humour: 2 (1.4), use of support: 3 (1.3), active coping or planning: $2(1.4)$, venting/self distraction: 2 (1.1), denial/self-blame: 3 (1.3) and acceptance: 2 (1.2). Low scores were observed in substance misuse: 1 (1.4) and behavioural disengagement: 0.7 (0.9). The mean (SD) of depression was 10 (6.6). Mild depressive symptoms were observed in $25.6 \%$ of patients. No relationships were found between coping strategies and adherence or between depression and adherence. The use of denial/self-blame as a coping strategy was related to higher levels of depression (OR: 1.182 [95\% CI: 1.0031.393]).

\section{Conclusion}

A high percentage of patients had adequate adherence after more than 10 years on treatment. The majority of coping strategies used to face the illness were active, except for denial/self-blame, which was associated with depression. In this study, adequate adherence was not related either to the use of active coping strategies or to the absence of depressive symptoms. 